\title{
Grupamento muscular da região anterior da coxa constituído por cinco cabeças: um relato de caso
}

\section{Muscular grouping of the anterior region of the thigh constituted by five heads: a case report}

Iago Caetano Cariello ${ }^{\dagger}$ Juliana Profilo Sampaio ${ }^{\dagger}$, Daniel da Silva Vianello ${ }^{\dagger}$, Layla da Silva Senra†, Luiz Guilherme Paixão Corrêa ${ }^{\dagger}$, Emílio Conceição de Siqueira

Como citar esse artigo. Cariello,

I.C.; Sampaio, J.P.; Vianello, D.S.; Senra, L.S.; Corrêa, L.G.P.; Siqueira, E.C. Grupamento muscular da região anterior da coxa constituído por cinco cabeças: um relato de caso. Revista de Saúde. 2019 Jul./Dez; 10 (2): 61-65.

\begin{abstract}
Resumo
O quadríceps femoral é descrito, didaticamente, como um grupo muscular composto por quatro cabeças de fixação proximal: o reto femoral (RF), vasto lateral (VL), vasto medial (VM) e vasto intermédio (VI). Todas elas apresentam a mesma inserção, inervação, vascularização e função. Estudos recentes evidenciaram a existência de um músculo novo no aparelho extensor do joelho, que foi nomeado como músculo Tensor do Vasto Intermédio (TVI). O objetivo desse trabalho é relatar a presença de um músculo adicional na região anterior da coxa de um cadáver do Instituto de Anatomia da Universidade de Vassouras, encontrado entre o VI e VL na região lateral proximal da coxa. Devido sua semelhança com os outros componentes do quadríceps femoral (mesma inserção, inervação e função), acreditamos que ele possa ser considerado uma nova cabeça do aparelho extensor e não um novo músculo. Ou seja, o quadríceps femoral passaria a apresentar cincos cabeças, ao invés das quatro tradicionalmente descritas.
\end{abstract}

Palavras-chave: Músculo quadríceps, Variação anatômica, Tensor vasto intermédio, Reto femoral, Vasto lateral.

\begin{abstract}
The femoral quadriceps is described as a muscular group consisting of four proximal fixation heads: the rectus femoris (RF), the vastus lateralis (VL), the vastus medialis (VM) and the vastus medialis (VI). All of them present the same insertion, innervation, vascularization and function. Recent studies have demonstrated the existence of a new muscle in the extensor apparatus of the knee, which was named as the Tensor Muscle of the Intermediate Vasus (IVT). The objective of this work is to report the presence of an additional muscle in the anterior region of the thigh of a cadaver of the Institute of Anatomy of the University of Vassouras, found between the VI and VL in the proximal lateral region of the thigh. Due to its similarity with the other components of the femoral quadriceps (same insertion, innervation and function), we believe that it can be considered a new head of the extensor apparatus and not a new muscle. That is, the quadriceps femoris would have five heads, instead of the four traditionally described.
\end{abstract}

Keywords: Quadricepsmuscle, Anatomicvariation, Tensorvastusintermedius, Rectusfemoris, Vastuslateralis.

\section{Introdução}

O quadríceps femoral representa o principal volume da região anterior da coxa e é considerado um dos músculos mais fortes do corpo. Sua inervação é realizada por ramos do nervo femoral (L2 - L4) e sua vascularização é composta por ramos da artéria femoral. ${ }^{1}$ Ele é composto por quatro cabeças de fixação proximal: reto femoral (RF), vasto lateral (VL), vasto medial (VM) e vasto intermédio (VI). Cada uma destas cabeças origina-se independentemente e se unem na parte distal, no tendão comum do músculo quadríceps, etodas possuem função de estender a perna e fletir o quadril..$^{1,2}$

Segundo estudos recentes realizados por Grobet al. ${ }^{2}$, existe a presença de um músculo novo no aparelho extensor do joelho. Willan et al. ${ }^{3}$ foi o primeiro a descrever a presença de uma lâmina muscular entre os tendões do VL e VI. Esta, mais tarde, através de um estudo cadavérico, foi encontrada em 26 cadáveres da população suíça por Grob et al. ${ }^{2}$, que descreveu o achado como um novo músculo do aparelho extensor do joelho, nomeando-o como Músculo Tensor do Vasto Intermédio. Depois disso, um estudo morfométrico do músculo foi realizado em cadáveres do Sul da Índia, em que o TVI foi

Afiliação dos autores: † Discente do curso de graduação em medicina. Universidade de Vassouras - Vassouras/RJ, Brasil.

¥ Docente do curso de Medicina. Universidade de Vassouras- Vassouras/RJ, Brasil

*Email de correpondência: iagoccariello@gmail.com 
encontrado em todos os 36 cadáveres dissecados. ${ }^{3} \mathrm{O}$ local de origem do TVI seria na parte superior da linha intertrocantérica e parte anterior do trocanter maior, enquanto sua inserçãoseria na parte superior da patela.

Para reconhecer tal estrutura é importante que haja o conhecimento da anatomia local e das principais variações da região. A morfologia do TVI é marcada por uma grande variabilidade, visto que o número e o tamanho dos ventres musculares; a largura da aponeurose e a fusão dessa aponeurose com o vasto adjacente é bem diversificada. ${ }^{4}$

Desse modo, o objetivo deste trabalho é relatar o caso de um músculo adicional na região anterior da coxa, encontrado em um cadáver do Instituto de Anatomia da Universidade de Vassouras, correlacionando-o com os achados literários descritos sobre o TVI.

\section{Relato de caso}

O presente estudo trata-se de um relato de caso de um cadáver humano do Instituto de Anatomia da Universidade de Vassouras em que foi dissecado a região anterior da coxa e encontrado um músculo adicional neste compartimento.

Durante um curso de dissecação da Liga de Anatomia Froés da Fonseca - Vassouras RJ, foram dissecados os membros inferiores, com foco no aparelho extensor do joelho, de um cadáver humano fixado em formol, do sexo masculino, com a peculiaridade de apresentar uma musculatura altamente hipertrofiada.

Foi realizada técnica de dissecação na tentativa de identificação do músculo TVI, que foi encontrado, em ambas as coxas, entre os músculos Vasto Lateral e o Vasto Intermédio, na porção proximal lateral da coxa (Figuras 1 e 2). Tal músculo apresentava sua fixação proximal na parte superior da linha intertrocantérica, próximo ao trocanter maior, e sua fixação distal no tendão do músculo quadríceps femoral. Seu ventre muscular na coxa direita media $24,6 \mathrm{~cm}$ de comprimento e na coxa esquerda 24,3 $\mathrm{cm}$ de comprimento. Sua inervação era a mesma do quadríceps femoral, ou seja, o nervo femoral.

\section{Discussão}

Experiências clínicas e estudos anatômicos, até pouco tempo, não confirmaram a presença do músculo TVI. Isso se devia a dificuldade da dissecação na área em que o músculo está presente, já que há inúmeros vasos e nervos nesta região, e a complexidade de identificação do músculo, devido ao fato da aponeurose do músculo TVI ser contínua e intimamente relacionada com as aponeuroses dos músculos vasto intermédio (VI) e lateral (VL).

Grob et al. $^{2}$ realizou a dissecação de 26 cadáveres da população suíça e, em todos eles, o descrito comonovo músculofoi encontrado e um ramo curto exclusivo do nervo femoral para seu ventre foi observado. Durante a prática da dissecção dessas peças, observou-se que em $42 \%$ dos casos o músculo mencionado encontrava-se de forma independente, ou seja, a aponeurose do TVI encontrava-se separada da aponeurose dos músculos VL e VI. Em 23\% dos casos, a aponeurose doTVI encontrava-se inseparável da aponeurose do VI, enquanto em 19\% a aponeurose do TVI era inseparável da do VL. No restante dos casos $(16 \%)$, a aponeurose do TVI encontrou-se inseparável das aponeuroses do VI e do VL.Além disso, o tendão do TVI, em sua parte distal, de todas as peças, fundia-se ao tendão do quadríceps femoral. ${ }^{2}$

Com o auxílio da ressonância magnética (RM), pôde-se demonstrar a existência do novo músculo, chamado TVI. ${ }^{2,4}$ No entanto, nem sempre é possível a visualização do músculo em questão através desse exame de imagem, uma vez que há uma proximidade muito grande entre o VL, TVI e VI, além de existir limitações da RM em reconhecer planos fasciais ou aponeuróticos ou distinguir componentes musculares adjacentes.

Os membros inferiores do cadáver dissecado no Instituto de Anatomia da Universidade de Vassouras apresentavam, em ambos os lados, um músculo adicional, com sua origem na parte superior da linha intertrocantérica, anterior ao trocantermaior, einserção no tendão do músculo quadríceps femoral. Porém, como o TVI apresenta a mesma inserção, a mesma inervação (nervo femoral), a mesma vascularização (artéria circunflexa femoral lateral) e a mesma função que os músculos do quadríceps femoral, acreditamos que este possa não ser um músculo novo, mas, sim, um novo componente do músculo quadríceps femoral. Isso corrobora para a hipótese deque o quadríceps femoral tenha cinco cabeças, ao invés das quatro tradicionalmente descritas, podendo a nova cabeça ser conhecida como Vasto Intermédio Superficial, enquantoa cabeça Vasto Intermédio passaria a ser intitulada Vasto Intermédio Profundo (Quadro 1). Sendo assim, o termo quintíceps femoral deveria ser utilizado em substituição ao nome quadríceps femoral. 


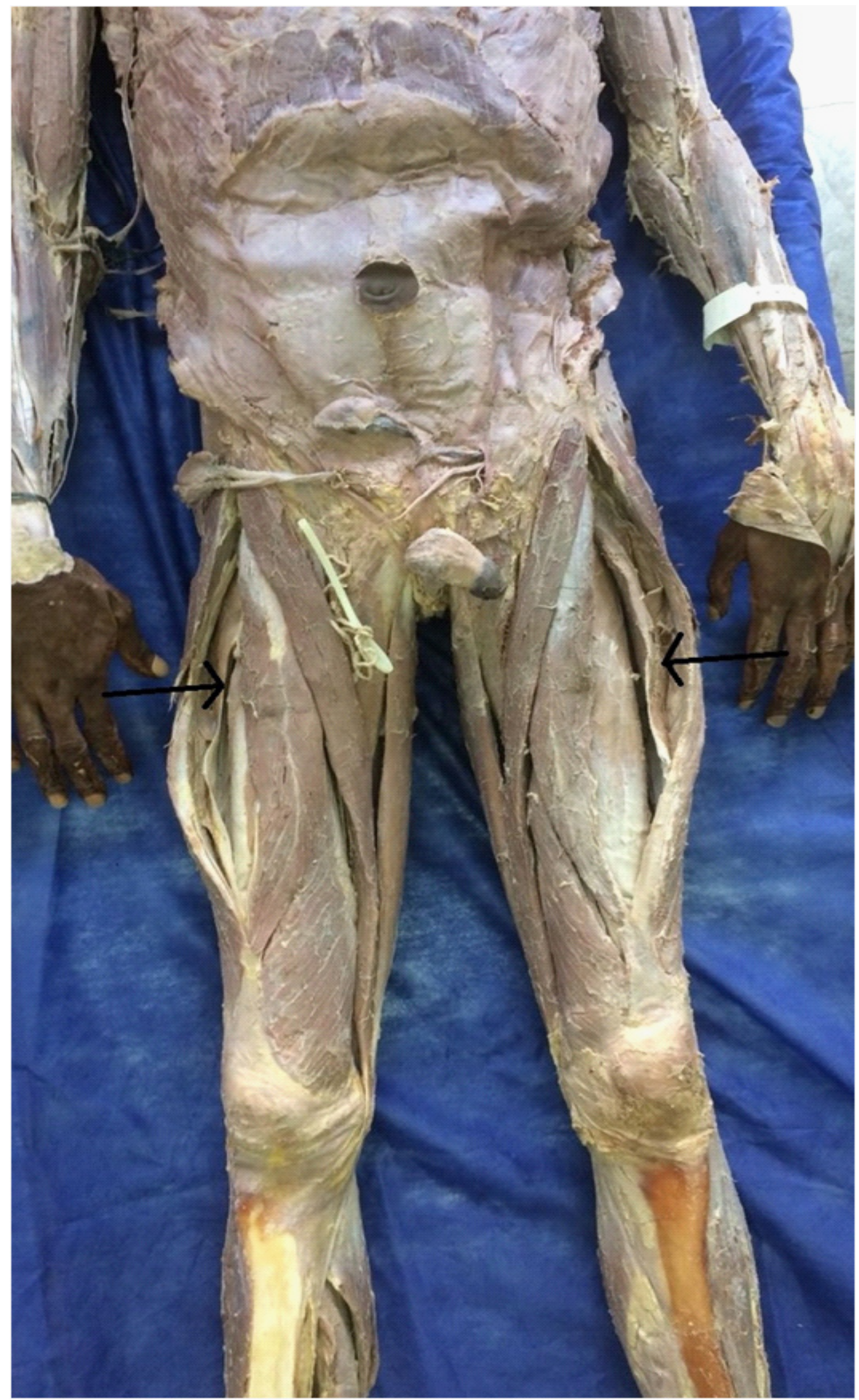

Figura 1. Setas apontam o ventre do músculo vasto intermédio superficial em cada membro inferior em um cadáver humano dissecado no Instituto de Anatomia da Universidade de Vassouras. 


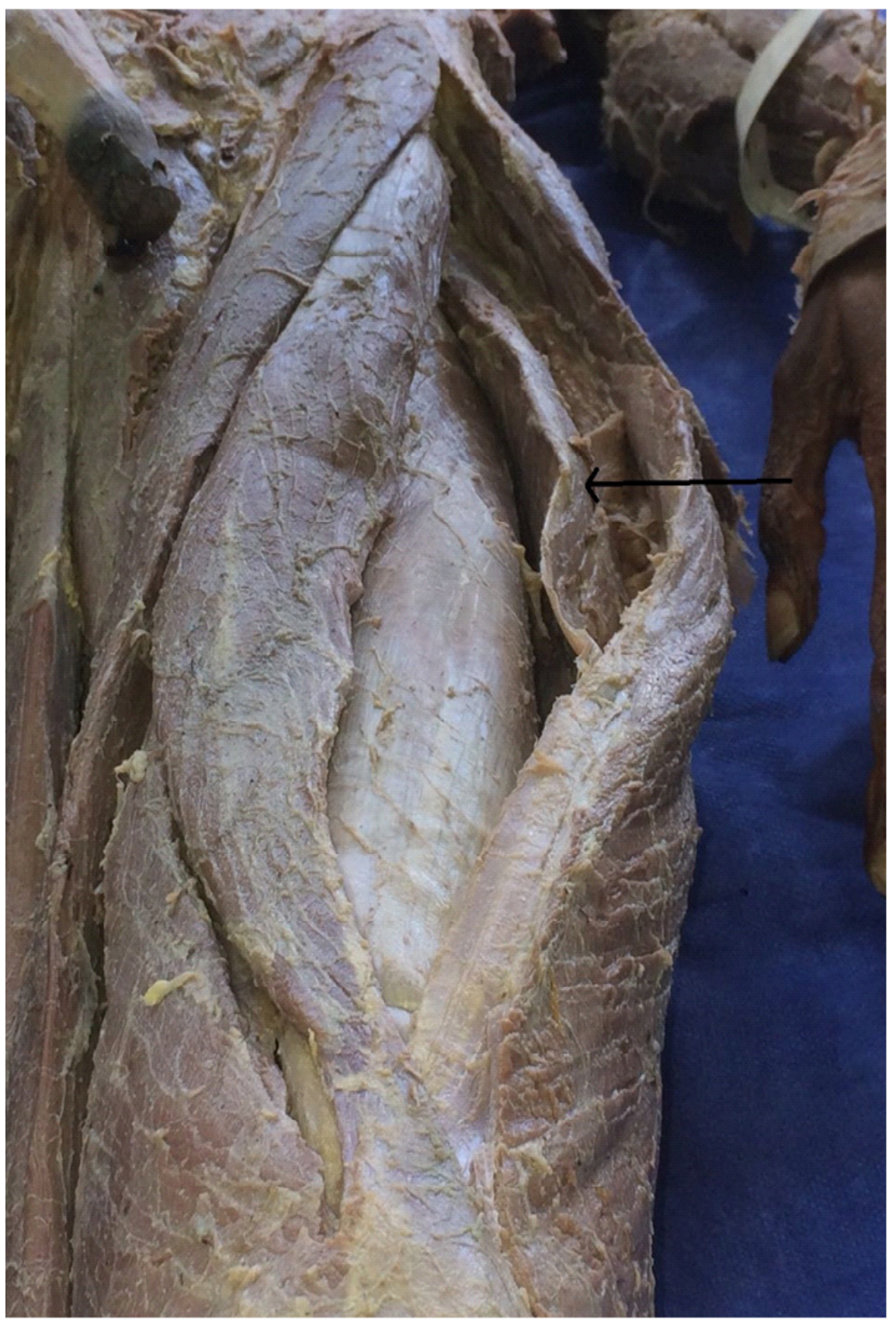

Figura 2. Seta indica ventre do Músculo vasto intermédio superficial de membro inferior esquerdo em um cadáver humano dissecado no Instituto de Anatomia da Universidade de Vassouras.

\section{Considerações finais}

Foi dissecado um cadáver humano do sexo masculino pelos alunos Liga de Anatomia Froés da Fonseca, onde foi identificado uma cabeça adicional do aparelho extensor do joelho. Devido a carência de artigos sobre o assunto, é necessário aprimorar os conhecimentos sobre o tema, pois o conhecimento daquela pode ter reflexões na mecânica da patela e extensão do joelho, inclusive nas cirurgias do aparelho extensor do joelho. Além disso, sua visualização em ultrassonografia pode ser confundida com uma tendinite do tendão do quadríceps, por gerar a aparência de um espessamento deste tendão ${ }^{3}$, o que faz necessário maior conhecimento anatômico do local.

Para isso, é importante ressaltar que como o intitulado Músculo Tensor do Vasto Intermédio apresenta a mesma inserção, inervação, vascularização e função dos músculos do quadríceps femoral, ele deve considerado uma nova cabeça (Vasto Intermédio 


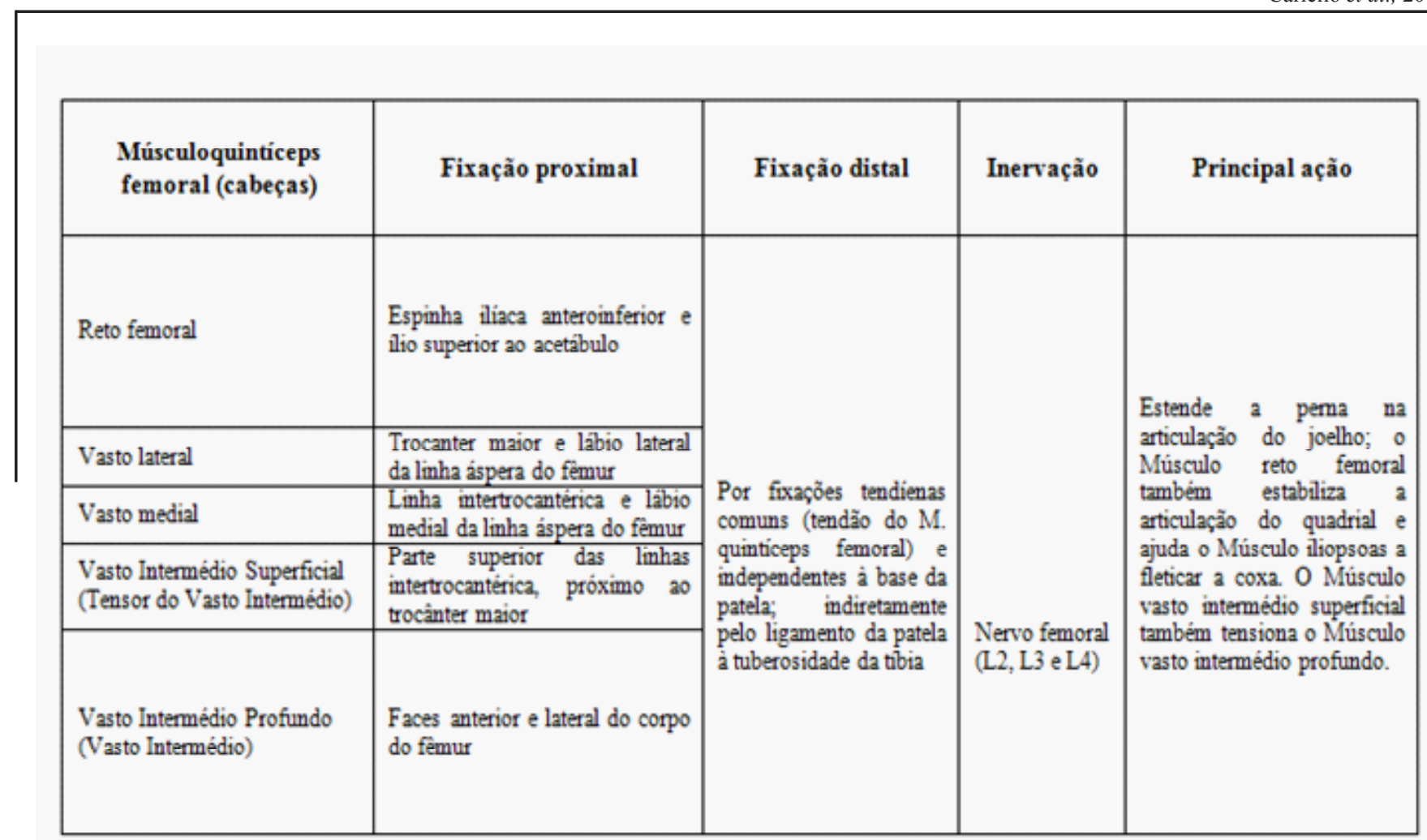

Quadro 1. Formação do quintíceps femoral após observação do músculo vasto intermédio superficial. Adaptado do Moore et al¹ .

Superficial) do quadríceps femoral, que passaria a ser denominado quintíceps femoral.

\section{Bibliografia}

1. Moore KL, Dalley AF, Agur AM. Clinically oriented anatomy. Lippincott Williams \& Wilkins. 2013. 7a. edição.

2. Grob K, Ackland T, Kuster MS,Manestar M, Filgueira L. A newly discovered muscle: the tensor of the vastus intermedius. Clinical Anatomy. 2016; 29(2):256-263.

3. Willan PL,Mahon M,Golland R, Jennifer A. Morphological variations of the human vastus lateralis muscle. Journal of anatomy.1990; (168): 235.

4. Grob K, Manestar M, Gascho D, Ackland T, Gilbey H, Fretz C, Kuster MS. Magnetic resonance imaging of the tensor vastus intermedius: A topographic study based on anatomical dissections. Clinical Anatomy. 2017; 30(8):10961102. 